\title{
In memoriam: Bob Hale
}

\section{Antonella Mallozzi ${ }^{1}$ (D)}

(c) Springer Nature B.V. 2019

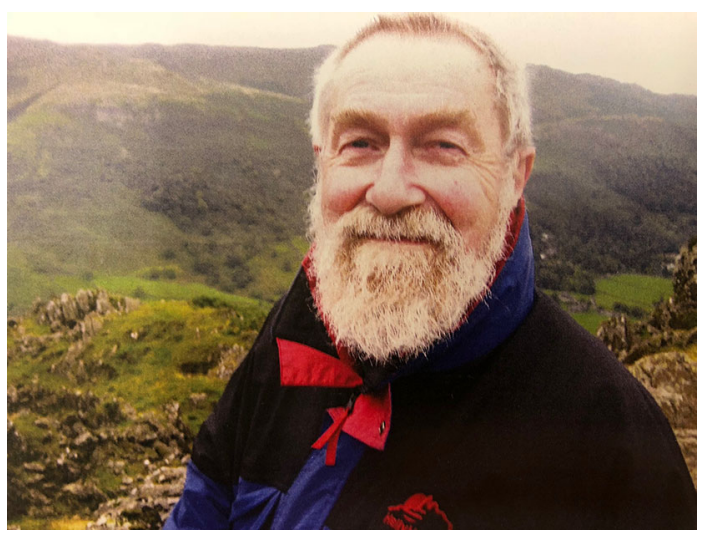

This Special Issue is dedicated to the memory of Professor Bob Hale, who passed away in December 2017.

He was an invaluable member of our philosophical community and will be sorely missed.

Publisher's Note Springer Nature remains neutral with regard to jurisdictional claims in published maps and institutional affiliations.

$\bowtie \quad$ Antonella Mallozzi

amalloz1@providence.edu

http://antonellamallozzi.com;

https://philosophy.providence.edu/

1 Providence College, Siena Hall 139, 1 Cunningham Square, Providence, RI 02918, USA 